\title{
Paved With Good Intentions: The Road Home and the Irreducible Minimum of Homelessness in Australia
}

\author{
Gary Johns ${ }^{1}$
}

\begin{abstract}
Despite public interest and public inquiries as long ago as the 1989 Human Rights Commission and the consequent increase in funding by the Hawke and subsequent governments, the 2006 rate of homelessness in Australia was 32 per 10 000, only marginally better than the 34.8 per 10000 of 2001. This article explores the reasons for the apparent failure to fulfil past promises and the weaknesses in current strategy. It argues for an explicit policy framework containing the assumption that there is an irreducible level of homelessness, and that there should be an assessment of the cost-effectiveness, probability of success and timeliness of each known remedy, in order to achieve the irreducible level.
\end{abstract}

\section{Introduction}

In its 2008 White Paper The Road Home, the Australian Government promised to halve by 2020 overall homelessness and offer supported accommodation to all rough sleepers who were deemed to need it. The then Prime Minister, Kevin Rudd, contended in the same document, that 'In a country as prosperous as Australia, no-one should be homeless' (FaHCSIA 2008a: Foreword). The apparent difference between Rudd's contention and his promise suggests a lack of political will. Or was it recognition that homelessness can be reduced, but is not solvable? The Rudd goal was no doubt a political aspiration, constrained by, on the one hand, the wish not to repeat Prime Minister Bob Hawke's promise of 1987 ('no Australian child will be living in poverty'2) and, on the other, a need to make sufficient 'announcement' impact. Indeed, the stated goal may amount to an implicit admission that, despite best endeavours, there is an irreducible level of homelessness.

1 Australian Catholic University; gary.johns@acu.edu.au

21987 Federal election campaign launch. 
This is not to ignore the exhortation to 'do better' that a goal implies, but an admission that an irreducible level of homelessness should, if proved, be made an explicit part of policy. Indeed, the goal of such policy may well be to reach the irreducible level of homelessness. Whether such level is 'half' the present level - or less, or more - is unknown. This paper proposes a way to discover the irreducible level of homelessness. The proposed method is to distinguish causes of homelessness and, for each cause, to assess the cost-effectiveness, probability of success and timeliness of each present remedy, and alternative remedies. At the same time, account is taken of measures that will reduce the stock of homeless and distinguish these from those that reduce the flow of homeless.

\section{Some history}

In 1989 the Australian Human Rights Commissioner, Brian Burdekin, reported on homelessness among the young in Australia in Our Homeless Children (AHRC 1989) and made homelessness a headline issue. He was appointed by a sympathetic government and he reported to a sympathetic Minister in Brian Howe, a member of a pro-intervention cabinet. The responses to Burdekin's recommendations were exhaustive and continued in subsequent administrations. Contributions under the Commonwealth State Housing Agreement rose from $\$ 1.27$ billion to $\$ 1.51$ billion in the period 1990-95 (HAA 2002: 105); funding for Supported Accommodation Assistance Program (SAAP) agencies ${ }^{3}$ increased to $\$ 400.4$ million by 2008 , a 28 per cent increase in real terms from 1996 , and the number of SAAP agencies increased from 500 to 1562 in the period 1985-2008 (AIHW 2009, 7: 297).

In 1993 the Australian Human Rights Commission conducted a national inquiry into the human rights of people with mental illness (AHRC 1993), which highlighted mental illness as a major factor in homelessness. Although the responses to the second inquiry were not as comprehensive as those that followed the first, there were nevertheless considerable changes to the treatment of those with mental-health problems (Ozdowski 2001). The new inquiries and the government responses unfortunately appear to have been insufficient, as the rate of homelessness recorded in the 2006 Census was 32 per 10000 of the population, down only marginally from 34.8 in 2001 (ABS 2011a: 78 and 90). ${ }^{4}$ These estimates have been subject to major adjustment as a result of substantial measurement issues, discussed below. This modest gain occurred in circumstances where employment rose 13 per cent, unemployment fell 22 per

3 Not-for-profit organisations that deliver support to the homeless.

4 Comparable data are not available in earlier censuses. 
cent, and disposable household incomes of low-income households rose 38 per cent in nominal dollar terms. By contrast, rents rose only 17 per cent during this period and rental vacancy rates remained above the 3 per cent 'neutral' level until at least the end of 2004. Reported domestic violence, which is the greatest single cause of homelessness, fell 22 per cent and the divorce rate fell 12 per cent between 1996 and 2005 (ABS 2011a: 12).

For declining to endorse the Rudd goal of halving homelessness, the Leader of the Opposition, Tony Abbott, was roundly criticised (Dunkerley 2010). Abbott was, in effect, arguing that many causes of homelessness - broken relationships, broken minds, broken hearts, and broken bodies - were not preventable. While each of these may be 'mended', they were not preventable in a large population. To the extent that these problems cause homelessness, homelessness cannot be prevented. The amount of time spent homeless or the amount of 'cycling' through poor housing may be diminished, but it is most improbable that causes of homelessness can be abolished. The Rudd Government was attempting to bypass difficult policy and political issues; respectively to admit which aspects of homelessness were not solvable and the implications for achieving the stated goal of halving homelessness.

Nevertheless, there are clear gains to the individual and to society from some programs for the homeless. As a result of receiving support from the SAAP homelessness program, for example, the homeless may use fewer other government services. One study of SAAP services (Flatau et al. 2008: 10) has found that budget outlays for all other programs consumed by the homeless are at least twice as large as the annual SAAP program cost. In other words, there are significant potential net government cost savings from providing assistance. For example, the average cost per client for SAAP-Single Men clients is $\$ 4625$; the associated saving is more than twice that amount, at $\$ 10212$, resulting in net cost savings of $\$ 5587$ per person per year (Ibid: 12).

These gains, however, address the 'stock' or extant number of homeless (or, at least, those who are eligible for SAAP services); they do not necessarily address the flow of new entrants. A well-run policy may not lower homelessness at all; rather, it may deal efficiently and effectively with an ever-refreshing stock of homeless people, returning them to better circumstances at least cost. The positive outcomes to homelessness programs should be applauded but their limits in reducing it should be recognised. Housing assistance in all its forms, for example, is channelled to those most in need (AIHW 2011: viii). Services to the homeless should not be an exception. Social triage is obviously important in this context and the great work of those in the field must be acknowledged. Arguably, however, once the point has been reached at which homelessness is 
irreducible the policy goal should switch from reduction per se to reduction of turnaround times for those for whom such remedies are appropriate and, where not possible, to long-term provision.

\section{The Road Home strategy - or lack of it}

The very large investment in public and private inquiries, public policy and public expenditure (not to mention the considerable efforts of the charitable sector) over many years until 2008 has not had the desired effect of reducing homelessness by much, let alone eliminating it. Indeed, and perhaps reflecting some frustration with the apparently intractable nature of homelessness, shortly after the White Paper was published, representatives of the welfare sector completed its own inquiry, an 'independent' community inquiry funded by the Caledonia Foundation, the National Youth Commission Inquiry into Youth Homelessness. The report called for $\$ 1$ billion of extra public funds over 10 years and, curiously, without offering its own, called for a government 'policy strategy' (NYC 2008: 374). Perhaps reflecting these apparent failures in strategy and funding, the Rudd Government announced a 55 per cent increase on the then current expenditure on homelessness, representing an additional \$800 million over four years (FaHCSIA 2008a: Foreword), and three strategies to halve homelessness. In unison with previous efforts, however, no argument was advanced in the White Paper about the relationship between expenditure and result.

Instead, the White Paper announced the strategies:

- 'Turning off the tap': early intervention to prevent homelessness, especially in families

- Services to end homelessness through training and employment, and

- 'Breaking the cycle': moving people quickly into supported accommodation. (FaHCSIA 2008a: chapter 2)

At face value, these strategies, coupled with a 55 per cent increase in funds, appear 'authoritative and rational' (Colebatch 2006: 42) and therefore constitute a solid foundation for public policy.

In fact, the goal, the funding and the strategies are less authoritative and rational than they appear. This is so because elements of the policy are assumed, not proved. The 50 per cent reduction goal is to be achieved by a combination of turning off the flow of the newly homeless; ending homelessness of the current stock more quickly; preventing the homeless from repeating the cycle; or, simply adding to the stock of accommodation and services for the homeless. Just how 
realistic each of these strategies is, or how much each of these distinct elements will contribute to the 50 per cent reduction or, indeed, how the funding of each will produce the best return is nowhere explained in the White Paper. Fifty per cent of new funding is to be devoted to prevention (FaHCSIA 2008a: chapter 2), for example, but it is unknown whether these funds will lessen homelessness by a proportionate amount. The services to end homelessness promise some new directions - for example, investing in individuals through the 'breaking the cycle' strategy - but the old directions - adding to the stock of accommodation and homeless services, which has been the 'standard strategy $^{\prime 5}$ of the sector for many years - remain.

While the Rudd Government established a Council on Homelessness ${ }^{6}$ and funded a national longitudinal survey of Australians experiencing homelessness or vulnerable to homelessness, ${ }^{7}$ it did not offer a strategic assessment of where the numbers to reduce homelessness were to be found. The data available to the Inquiry on the cost of homeless services were limited (Pinkney and Ewing 2006; Flatau et al. 2008) but this should not have prevented an intention to establish a least-cost pathway to reach the goal. Knowing how much to spend on what programs would seem a necessary step in either achieving the goal or proving its validity. It appears, however, that the government had no idea which strategy would contribute to what amount of reduction, at what cost or, indeed, whether the goal was feasible, too ambitious or not ambitious enough. It should have been possible at least to conceive an analysis that would inform such a strategy.

The object of the remainder of the paper is to suggest such an analysis, commencing with a review of the number and characteristics of the homeless, an assessment of the causes of homelessness, the strengths and limitations of current programs, and an assessment of where and what reductions are likely. New goals for homelessness policy are recommended.

\section{Measurement issues}

The headline homeless figure at the time of the White Paper, drawn from the 2006 Census, was 105 000. This was composed of 16000 actual homeless (those sleeping rough) and 89000 potential homeless. The Australian Bureau of Statistics has, however, recently revised down massively its 2006 (and 2001)

\footnotetext{
5 From author's conversation with Lin Hatfield Dodds, Uniting Care Australia, during the development of the paper.

6 Communiqué from Meeting 9, Sydney, 12-13 May 2011.

7 The Melbourne Institute of Applied Economic and Social Research, 'Journeys Home: longitudinal study of factors affecting housing stability'.
} 
Census estimates (ABS 2011a: xi). The 2006 revised amounts are 8000 actual homeless and 55000 potential homeless. (It seems, thus, that Prime Minister Rudd's promise has been reached before his programs started). The reasons for the revisions are many; but, in short, the ABS estimated homelessness using the Census when it did not include a homeless indicator. This meant that while some groups of homeless people were unobservable in the Census data, several other groups who were observable, but not homeless, were counted as homeless. For example, construction crews and owner builders, young professionals travelling overseas, and people following mobile employment opportunities were counted as homeless (ABS 2011a: 1). Making inferences about the observable - indeed, searching for the homeless in nonsensical categories - has brought the count into grave error. Accepting the revisions and, in the light of previous persistence of homelessness, there is, nevertheless, the question of how a government should proceed to achieve the goal of lowering homelessness. There are a number of relevant considerations.

The number of homeless reported at the 2001 and 2006 censuses (see Table 1) is estimated at one point in time and represents the stock of homeless. The number who experience at least one period of homelessness in a year is considerably higher and represents the flow of homeless (more than 300 000: ABS 2011c). The extent of recycling has implications for reducing homelessness; indeed, it needs to be borne in mind that there is a considerable amount of recycling in the flow numbers. In a study of homeless people in Melbourne, for example, 92 per cent had moved from one form of temporary accommodation to another - friends or relatives, boarding houses, supported accommodation - and had slept rough (Johnson and Chamberlain 2008: 342). As with the estimation of the stock of homeless, there is also the potential to overestimate the flow of homeless. In SAAP, for example, while a person who has multiple support periods in a single financial year is only counted as one client, they may record a client twice when his or her support period extends over two reporting periods (Flatau et al. 2008: 212). In relation to services for the homeless, the stock measure is generally most useful because these services are required on a daily basis, regardless of the flow through the services. Nevertheless, the length of time that a client requires a service or accommodation is crucial to overall resourcing.

The ABS was persuaded to adopt a cultural definition of homelessness. The cultural definition 'identifies shared community standards about the minimum housing that people have the right to expect' (ABS 201 la: 1). The accommodation categories - tertiary, secondary, primary ${ }^{8}$ — are a valid way of gaining a sense of who is at risk of homelessness - those staying in boarding houses, or in supported accommodation (for example, a women's refuge), or with friends.

8 Primary being actual homeless, and secondary at considerable risk of, and tertiary, at some risk of homelessness. 
While the concept is useful in enumerating the potential pipeline of homeless that is, those who sleep rough - it runs the risk of overstating the case for the homeless. Others have cautioned against the tendency for 'a single big number ... for advocacy purposes' (Pinkney and Ewing 2006: 12). Understanding the market in homelessness is fine; distinguishing the potential flow that may feed primary homelessness is legitimate; but building the numbers for advocacy is not helpful in as much as this may concentrate policy on accommodation and away from homeless services. Indeed, it may carry the implication that sufficient investment in accommodation, 'business as usual', will solve the homelessness problem.

The implication comes to grief in the first three categories of homelessness in Table 1. These define homelessness by their housing 'solution'. This mixes problems with solutions. A boarding house, SAAP, or staying with friends and family is an adequate solution for some people. There is an unstated assumption in a cultural definition of homelessness that there is some other remedy; for example, that it is realistic to expect a house to be readily available at short notice for the right price in the right area for those with short-term problems. The recent General Social Survey estimated that of those who had experienced homelessness, 13 per cent were homeless for less than a week, a further six per cent were homeless for less than two weeks, and another 12 per cent were homeless for less than four weeks (ABS 2011c). Some forms of accommodation presently relied on in government programs may well be all that is realistically available or, indeed, necessary.

Table 1: The homeless, defined by their accommodation

\begin{tabular}{|l|l|r|r|}
\hline Homeless 'accommodation' & Homeless category & 2001 & 2006 \\
\hline Boarding houses & Tertiary & 23748 & 16828 \\
\hline SAAP & Secondary & 13420 & 17331 \\
\hline Friends/relatives & Secondary & 17877 & 19579 \\
\hline Persons in other temporary lodging & Primary & 1395 & 1970 \\
\hline Rough sleepers, improvised dwellings & Primary & 8943 & 7764 \\
\hline Total & & 65384 & 63472 \\
\hline
\end{tabular}

Sources: ABS 2011a: tables 1.1 and 1.2,4-5, and ABS $201 \mathrm{lb}$. The figures are the result of census estimation, not a statistical estimate and thus are reported exactly, rather than rounded.

The situation for the long-term homeless is different. Twenty-two per cent spent six months or more without a permanent place to live (ABS 2011c), typically single men in boarding houses and women in supported accommodation (ABS 2008: 33). For these people the issues may be more difficult than for shorttermers. The issue for the latter is how long someone can be supported without recourse to institutional care. 
The cultural definition of homelessness also implies that there are solutions to forms of homelessness other than staying with friends/relatives. The inclusion of the friends/relatives category implies that a family-based solution is not acceptable and that there is no solution without government assistance. Staying with friends and family seems a legitimate course of action. In fact, the greatest overestimation in homelessness was in the category 'staying with friends and family', which in 2006 was 19 579, down from 46856.

Similarly, it is implied that boarding houses are not a legitimate solution for some people, even long term, or that refuges are not essential solutions to those who need safety on a short-term basis. Non-specific or open-ended solutions implied by these categories are part of the difficulty of addressing homelessness. It is a contest between an assumed norm that does not exist and the reality of a very long commitment by a sector and governments to assist those who need assistance of varying types and kinds that, nevertheless, falls short of a solution.

\section{Seeking the irreducible minimum of homelessness}

The reasons why people are homeless, rather than their form of accommodation, may provide a far stronger clue to the necessary remedy to their problems. Indeed, the fact that an array of disparate people shares a similar problem may well cloud the nature of the remedies that need to apply. The causes of homelessness as established by the White Paper include a shortage of affordable accommodation, which may indicate a problem with the housing market, the remedies for which may be taxation or regulation (AHURI 2003; AHURI 2011). But this may have very little to do with remedies associated directly and specifically with the problems of other homeless people.

The problems of family breakdown are often entirely different in nature from those of affordability (although there will be affordability consequences in family breakdown) and exist in a realm where the remedies will be very different from the market-based remedies associated with affordability. Affordability issues may realistically be solvable; the problems of family breakdown, less so. Unemployment, like affordability, may be a market problem; then again, if unemployment is related to drug, alcohol and mental-health issues, finding someone a job will not be the solution to their housing problem. Those with drug, alcohol and mental-health problems encompass socio-cultural and medical dimensions, the remedies for which are different again from those of affordability and family breakdown. The homelessness of Aborigines is probably entirely different again from any of former, as the causes are both cultural and economic. 
The diverse nature of those who are homeless, and the diverse nature of the remedies, will have a major impact on estimating the irreducible level of homelessness. Identifying the baseline level of homelessness expected under 'normal' conditions may be difficult but it should help to frame the goals of homelessness policy. With some concept of a baseline, and appreciating that feasible 'remedies' can be time- and place-specific according to what the society can afford or demands (Galston 2006: 545), the baseline feasibility criteria serve to underline that solutions may not be available for all categories of need. The most effective remedies applied to each distinct category of need should reveal the difficult cases and the limits to solutions. A differentiated approach will raise sensitive issues about priorities, but a non-differentiated approach leads policymakers to chase a goal that is not achievable.

The White Paper makes a number of naïve statements, claiming (hopefully), for example, that the policy 'provides a framework for preventing homelessness from occurring in the first place' (FaHCSIA 2008a: Foreword). It boasts strategies to increase support for victims of domestic violence to stay safely in their own home, for example, but it does not inspire confidence that such a strategy reduces homelessness. Is there housing support for the perpetrator, for example, who may become homeless as a result of a safety-first strategy? The policy of 'no exits into homelessness' from hospitals, mental-health and drug and alcohol services and statutory care sounds promising but, of course, it is predicated on there being no solution to the problems for which hospitals, jails and other institutions are the intermediary solution. The flow remains; the stock needs to be addressed.

In order to fulfil the promise of lowering homelessness, governments and the sector need to think through a number of links in the chain of strategies and remedies applied to homelessness. The suggested model consists of understanding the limitations (cost-effectiveness and acceptability) in each strategy - turning off the tap, quicker turnaround, better services - and the attendant remedies for each type (cause) of homelessness.

The irreducible level of homelessness and the reasons why it is irreducible needs to be identified. Where such admissions are left unstated there is a risk of wasted effort or adverse consequences. For example, 'full employment' is defined well above zero unemployment for various reasons to do with the mismatch of skills required and skills offered in a market. There is, for all practical purposes, an irreducible number below which unemployment is unlikely to drop. Further, efforts to reduce the number may have inflationary consequences once the level is reached. Indeed, there is a measure, the non-accelerating inflation rate of unemployment (NAIRU), which represents equilibrium between the state of the 
economy and the labour market. By analogy, if indeed there is an irreducible level of homelessness, it follows that the idea of a homelessness 'solution' may have to be redefined.

Attempts to lower homelessness below the irreducible level could constitute inducements to leave present situations with friends and family to access government services. The inducement effect of accommodation services has recently been observed in a review of SAAP services. The study concluded that 'an increase in capacity may have flow-on effects on the number of people seeking accommodation because, as supply increases, so too might the demand for that accommodation' (AIHW 2010: 62). In other words, the availability of more beds in the sector could result in an increase in the demand for accommodation. The figures in Table 1, for example, indicate an increase in those seeking SAAP services and a diminution of those seeking boarding-house services between 2001 and 2006. The shift may have been caused by the substantial lift in investment in SAAP in the period (AIHW 2009, 7: 9). An attractive set of services for the homeless may simply shift effort from individuals to the taxpayer and NGOs for example, from friends and family to SAAP services, or between one form of government assistance to another — without solving anything.

Moving in the opposite direction, many of the places accommodating those with mental-health and substance-abuse problems have been closed in the last 20 or 30 years. The policy aspiration was that people should live in 'the community'. Unfortunately, the policy of de-institutionalisation sometimes resulted in people remaining uncared for and liable to end up on the street. The Mission Australia Centre and the Foyer model, discussed below, are examples of new institutions where people will receive their services in situ. The mentally ill and long-term drug dependent may well require new institutions. Reaching the goal of the irreducible level of homelessness may be impossible without revisiting institutions and their place in the suite of available remedies.

Similarly, if the proximate cause of homelessness among Aboriginal people is a lack of engagement in the economy, supplying public housing in the middle of an area where there are no jobs will not constitute a remedy. The best prospects for a solution may be in migrating to centres with job opportunities (Johns 2008). The policy suite itself may need to change in order to reach the goal of either halving homelessness or reducing the irreducible level of homelessness.

\section{Assessing causes}

Reaching the goal of irreducible homelessness requires a reasonable estimation of the number of people affected by each cause. There appears to be no consolidated account of the causes of homelessness sufficient to account for the 
entire cohort. The most plausible approach is to use surveys of those using SAAP services. Although SAAP services constitute less than 30 per cent of the total number of homeless and care must thus be taken in interpreting the figures as a representation of the homeless, they are, nevertheless, accurate in their own realm. As for other forms of homelessness and their causes, the data are unhelpful; there is only notional data on causation for those in boarding houses. Nevertheless, it is certain that most of those who pass through SAAP and boarding houses have also slept rough and/or stayed with friends. In other words, cycling is common and so the distribution of causes of homelessness as measured for SAAP may be a reasonable representation of causation throughout the sector (with the proviso that more single men attend boarding houses and more women and younger people access SAAP services). The categories are not exclusive; for example, 'those being unable to afford accommodation' may be unemployed. And 'previous accommodation ended' may be caused by financial hardship but may be from any other cause which led to the person being there in the first place.

\section{Table 2: Estimating the proportion of homeless by cause}

\begin{tabular}{l|l|r|}
$\begin{array}{l}\text { Homelessness causes } \\
\text { (The Road Home 2008) }\end{array}$ & $\begin{array}{l}\text { Homelessness causes of those accessing } \\
\text { SAAP services }\end{array}$ \\
\hline \multirow{2}{*}{ Shortage of affordable accommodation } & $\begin{array}{l}\text { Usual accommodation unavailable/ } \\
\text { overcrowding }\end{array}$ & 18 \\
\cline { 2 - 3 } & Financial difficulty & 15 \\
\cline { 2 - 3 } & Eviction/previous accommodation ended & 17 \\
\hline \multirow{2}{*}{$\begin{array}{l}\text { Emergency response to family violence } \\
\text { Youth separation from family }\end{array}$} & $\begin{array}{l}\text { Time out from family/other situation/ } \\
\text { interpersonal conflict }\end{array}$ & 12 \\
\cline { 2 - 3 } & $\begin{array}{l}\text { Relationship/family breakdown and } \\
\text { domestic/family violence }\end{array}$ & 32 \\
\cline { 2 - 3 } & Physical/emotional abuse/sexual abuse & 3 \\
\hline \multirow{2}{*}{ Unemployment } & $\begin{array}{l}\text { Recent arrival to area with no means of } \\
\text { support }\end{array}$ & 4 \\
\hline Long-term mental health & Mental health/other health & 6 \\
\cline { 2 - 3 } & Recently left institution & 4 \\
\hline Substance abuse & Drug/alcohol/substance abuse & \\
\hline
\end{tabular}

Sources: Australian Institute of Health and Welfare 2008: 32.

Table 2 contains estimates of people who access SAAP services, categorised by the cause of their homelessness. Understandably, people who need SAAP services because of a shortage of affordable accommodation are a prominent proportion of those surveyed. It is not clear, however, whether their 'financial difficulty' or the 'usual accommodation becoming unavailable' is the consequence of some crisis event. For example, domestic violence has consistently been the major reason people seek support from specialist homelessness services during the life 
of SAAP; as a consequence, 80 per cent of SAAP recipients are single parents. The categories of relationship and family breakdown and family violence represent more than 30 per cent of the reasons why people use its services. Moreover, there is evidence to indicate that a similar proportion use boarding houses for the same reason (Anderson et al. 2003: 4). Much has been made of the incidence of mental-health and substance-abuse problems as a cause of homelessness. The SAAP figures, however, indicate that these are not as great as implied in the White Paper.

The data on Indigenous homelessness in remote areas are confusing. The total number of homeless in remote areas constitutes six per cent of all causes. Although it is assumed that most would be Indigenous, there is no definitive figure. Aborigines constitute 18 per cent of all SAAP users, but the 2006 Census dataset classified Aborigines as 10 per cent of all homeless persons. However, Indigenous status is not reported for a significant proportion of those who were classified as homeless (14 per cent). If those people for whom Indigenous status was not provided are excluded from the calculation, Indigenous people make up 12 per cent of the reviewed estimates of homeless people (ABS 2011b).

\section{Assessing remedies}

The most common remedies presently available to address homelessness are income support and, as noted above, various forms of supported accommodation. Specific 'new' remedies, those being trialled to address particular groups of homelessness (often emphasising services in addition to shelter) place a great emphasis on prevention and rehabilitation. As noted above, 50 per cent of the new funding is being devoted to the prevention strategy. Although not well specified in the White Paper, these programs are designed to keep families together, concentrate on the prevention of domestic violence and to minimise risk to children in the home. Other strategies contribute to the most efficient and effective return of those who are homeless to a more permanent housing situation. Which remedy contributes to which strategy and by how much is not apparent from the White Paper. Nevertheless, a selection of major new remedies is set out below and briefly reviewed with respect to their strategic contribution and efficacy:

\section{Family violence}

A recent overview of women, domestic and family violence, and homelessness concluded that 'a substantial part of the solution in terms of strategies that prevent domestic and family violence related homelessness are those that prevent domestic and family violence from happening in the first place' 
(FaHCSIA 2008b: 31). Unfortunately, the synthesis report did not quote a single instance of a successful program to prevent violence. While case studies were quoted, no proof was presented to indicate why, how or, indeed, if (other than by the author's word) these were successful. This study, if it is the best available, does not provide a single figure to indicate any program that may have reduced domestic violence and that may, in turn, have reduced homelessness. The COAG report National Plan to Reduce Violence Against Women and Their Children (COAG 2010), contains nothing more than targets and recitations of many of the same programs in the FaHCSIA report.

The NSW Auditor General found a reduction in family violence rates for Aborigines in the period 2002 to 2008 although no evidence was presented that proved the programs had anything to do with the result (NSWAG 2011: 17 and 30). The NSW Ombudsman reported that the Safe Families program in NSW, aimed at reducing sexual assault against children in Aboriginal communities, was operational in only two of the five proposed locations and that a total of six families in Wilcannia and two families in Lightning Ridge had received case management! The funding for Safe Families was \$22.9 million, and is now entering its final year of operation (NSWO 2011: 21).

These two foundation documents and the NSW case studies leave empty the central strategy of the largest component of the White Paper homelessness strategy. On the basis of this evidence, these contributions to the "turn off the tap' strategy are unlikely to yield much reduction in homelessness.

\section{The 'Foyer' model}

In the Foyer model each 'Foyer' is managed by a steering group made up of local members of the public, elected representatives, business people and professionals so as to assist homeless youth to prevent cyclical homelessness. The first Foyer model implemented in Australia is the Live ' $N$ ' Learn Campus (Miller Campus) based near Liverpool in NSW. The centre includes life-skills training - for example, skills to obtain and maintain a tenancy, healthy cooking and budgeting - as well as more formal skills acquisition. In strategy terms, it is appears to aim to 'turn off the tap' and 'end homelessness'. An evaluation of the Live ' $N$ ' Learn Campus (AHURI 2006: 4) indicates promising results. The model raises the question of the extent to which Foyer is an institution, and whether this will be the first of other attempts to reinvest in institutional care.

\section{The Reconnect program}

The Reconnect program (FaHCSIA 2003) funded by the Commonwealth government uses community-based early-intervention services to assist young 
people aged 12 to 18 years who are homeless, or at risk of homelessness, and their families. Young people using Reconnect have, for the most part, not yet left home or have only recently left home. This program fits squarely the 'turning off the tap' strategy. An evaluation of the program found that Reconnect has been successful in improving stability in young people's living situations (FaHCSIA 2003: 8). Young people living in temporary situations fell from 16.5 per cent at Reconnect's initial intervention to 5 per cent at exit from the services. Reconnect intervention also increased the stability of young people's living situations in relation to parents - young people living with parents increased from 58 per cent at the start of support to 62 per cent after support (FaHCSIA 2003: 9). The evaluation contained no cost data, but the program nevertheless appeared to be mildly effective.

\section{Outreach teams}

One particular program, Street To Home, was established in 2004 and aims to find accommodation solutions for people sleeping rough in Inner Adelaide. It sees the provision of housing as a first step out of homelessness and therefore sits squarely in the 'breaking the cycle' strategy. The agency provides services over extended hours and staff work to locate, identify and engage with rough sleepers through a case-management response to help individuals make the transition from homelessness into secure housing. The available evidence is that, as of 2007, the service had 'assisted 40 of the inner city's most chronic rough sleepers into long-term sustainable housing. It ha[d] also helped 108 people into long term accommodation, with a 99.5 per cent retention rate; 177 have been referred to mental health services' (Newman 2007: 41). The referrals raise the prospect that long-term solutions for some of the mentally ill may require more permanent and formal institutional arrangements. Unfortunately, there is no cost-effectiveness analysis available to indicate if the program has succeeded.

\section{Mission Australia}

Mission Australia recently decided to use its funds to provide high-quality crisis accommodation to 40 people, where previously it provided accommodation to 110. Under the new model, clients receive 32 different professional services, including training, educational and other services, which are delivered to these 40 people on site (Mission Australia 2009). This switch in service from quantity to quality clearly required considerable strength of management because it denied a bed to 70 other men. Unfortunately, there was no cost-benefit analysis to prove that the sacrifice was worth it, the report simply stating that 'goals had been achieved' and 'programs delivered', although there were improved accommodation and employment outcomes after one year (Ibid: 22). None of the 
costs attributed to the program were assigned to the outcomes. There is a clear attempt to reduce the recurrence of homelessness, which fits the government's strategy to end homelessness. This remedy shows promise and may play some part in reducing not only the stock of homeless but that part of the flow of homeless attributable to 'cycling'.

\section{National Partnership Remote Indigenous Housing}

The National Partnership Remote Indigenous Housing funding of \$5.5 billion over 10 years ( $\$ 1.94$ billion new funding plus previous funding allocated under the Australian Remote Indigenous Accommodation Program funding of \$3.55 billion) will provide up to 4200 new houses in remote Indigenous communities and upgrades to 4800 existing houses through a program of major repairs and/ or replacement (Macklin and Rudd 2008). The $\$ 5.5$ billion will be spent in 26 priority settlements. All but two of these settlements are former missions or government ration stations and each is almost wholly or predominantly Aboriginal (Johns 2011: 255).

This program should, by increasing the amount of available and affordable housing, presumably satisfy strategy three, breaking the cycle. Unfortunately, this program is perhaps destined to be the largest and least-effective intervention. Economic prospects are slight in almost all of the 26 preferred settlements (Ibid: 255). The Government's criteria for selecting them were that there was significant concentration of population and that there were pre-existing shortfalls in government investment in infrastructure and services. The Government suggested that there was potential for economic development and employment, but no data to justify the selection accompanied the announcement.

It should be possible to use existing knowledge to assess the cost-effectiveness, probability of success and timeliness of known remedies for each sector of the homeless market in order to establish priorities and as a means of judging whether a goal is achievable. Unfortunately, the brief survey above suggests there is much to be done to inform policymakers. A recent major study aimed at developing costing of homelessness programs found that 'existing (or at least, publicly available) cost information is not adequate for the purposes of evaluation research' (Pinkney and Ewing 2006: viii). A recent review of SAAP services (AIHW 2010) suggests, however, that sufficient data are available for that service. Where data are inadequate, one possible means of investigating the strategic approach to estimating a pathway to the irreducible level of homelessness is to establish likely scenarios of different forms of homelessness (Kenway and Palmer 2003). While the cost data may not be precise, it should nevertheless be possible to assign nominal values to the effectiveness, probability 
and timeliness of remedies. The resulting matrix - causes and their remedies - may be a useful guide to policymakers to suggest where best returns on expenditure might be found.

\section{Conclusion}

It is possible, based on an assessment of the numbers and the remedies, and the review of evaluations immediately preceding, to derive some sense of where the gains may or may not come for each cause and remedy. Where the cause of homelessness is a lack of affordable accommodation, it may be that there are low-cost and fast remedies, and a high probability of success, but these may apply only to a few homeless people. By contrast, where the cause of homelessness is domestic violence, costs may be moderate if the turnaround is swift, and prospects of success with effective programs good, but the prospects for stemming the flow of new entrants may be low. Where the cause is mentalhealth problems, the gains will depend on the acceptability of the remedy, and the only real prospect for reducing homelessness may be in offering institutional accommodation on a long-term basis. Substance-abuse costs are likely to be high (especially for long-term addictions), probability of success low, and remedies slow. The cost of solving Aboriginal homelessness in remote areas is very high and the probability of success low; prospects may be improved under different remedies that were not tied to land.

This brief review of the major new remedies for homelessness, their cost (where possible), probability of success, timeliness, and the proportion of the homeless population to which they apply, suggests the prospects for reducing homelessness are limited. The few new remedies currently available, and those in prospect, are unlikely to yield large reductions. The greatest cause of homelessness is family breakdown and, as there is no known solution but readily available short-term assistance, it may be time for policymakers to reset their targets towards the efficient turnaround of the short-term needs and sufficient investment in longterm needs.

Regrettably, the Australian Government White Paper does not provide a convincing path to achieve its goal of halving homelessness. It is clear that a strategic analysis is needed, one that disaggregates the components of the homeless market, and reconsiders feasible remedies. Although the exercise on this occasion is but a brief overview, the technique does allow a policymaker to understand the likely gains in reducing homelessness and the likely areas which will be difficult to reduce. Governments may have to accept that efforts to reduce the stock of homeless will do no more than provide quicker short-term turnaround and more long-term places. Efforts to diminish the flow of homeless 
will depend on market conditions for housing and employment outside of the field of homelessness services. As for the large component of homelessness arising from family breakdown, the remedies are not obvious and may be beyond the scope of government programs.

Above all, the concept of a 'single homeless policy' and a single aim to meet a specific reduction in the numbers of homeless is fraught, and probably obscures the important distinctions in the causes for homelessness among distinct groups of people. Homelessness can be reduced for some, but probably not for all where the boundaries of acceptable policy remain limited. The Government needs a more articulated response to an enduring problem. It should accept that in a country as prosperous as Australia, there is an irreducible level of homelessness.

\section{References}

Anderson, P., Rogers N., Stephenson, T. and Hume A. 2003, It's No Palace Boarding Houses: the sector, its clientele and its future, Department of Human Services South Australia.

Australian Bureau of Statistics 2008, Counting the Homeless 2006, Australian Census Analytic Program.

2011a, 'Methodological Review of Counting the Homeless 2006', Discussion Paper.

2011 b, 'Review of Counting the Homeless Methodology', Position Paper.

2011c, General Social Survey: Summary Results, Australia, 2010.

Australian Institute of Health and Welfare 2008, 'Homeless people in SAAP', SAAP National Data Collection Annual Report 2006-07 Australia.

2009, Australia's Welfare 2009.

2010, Demand for government-funded specialist homelessness accommodation 2008-09, a report from the SAAP National Data Collection.

2011, Housing Assistance in Australia 2011.

Australian Housing and Urban Research Institute 2003, 'Tax Concessions and Subsidies for Australian Homebuyers and Home Owners', Research and Policy Bulletin 27.

2006, 'Youth Homelessness in Rural Australia', Research and Policy Bulletin 82. 
2011, 'How Do Planning Requirements Impact Housing Costs and the Development Process?' Research and Policy Bulletin 125.

Australian Human Rights Commission 1989, Our Homeless Children. 1993, The Human Rights of People with Mental Illness.

Colebatch, H. K. 2006, 'Accounting for Public Policy in Australia', Public Policy $1(1)$.

Council of Australian Governments 2010, National Plan to Reduce Violence Against Women and their Children.

Department of Families, Housing, Community Services and Indigenous Affairs 2003, 'I'm looking at the future', Evaluation Report of Reconnect.

2008a, The Road Home: Homelessness White Paper.

2008b, Women, Domestic and Family Violence and Homelessness: A Synthesis Report.

2010, Evaluation of the Child Protection Scheme of Income Management and Voluntary Income Management Measures in Western Australia.

Dunkerley, S. 2010, 'Abbott Rejects Rudd's Plan for Homeless', Sydney Morning Herald February 17.

Flatau, P., Zaretzky, K., Brady, M., Haigh, Y. and Martin, R. 2008, 'The CostEffectiveness of Homelessness Programs: A First Assessment', Volume 1 - main report Australian Housing and Urban Research Institute Western Australia.

Galston, W. 2006, 'Political feasibility: interests and power' in Moran, M., Rein, M. and Goodin, R. (eds.), The Oxford Handbook of Public Policy, Oxford University Press.

Housing Assistance Act 1996, 2002, Annual Report 1999-2000.

Johns, G. 2009, No Job, No House: An Economic Strategic Approach to Aboriginal Housing, Menzies Research Centre.

2011, Aboriginal Self-determination: the Whiteman's Dream, Connor Court.

Johnson, G. and Chamberlain, C. 2008, 'Homelessness and Substance Abuse: Which Comes First?' Australian Social Work 61(4). 
Paved With Good Intentions: The Road Home and the Irreducible Minimum of Homelessness in Australia

Kenway, P. and Palmer, G. 2003, How many, how much? Single homelessness and the question of numbers and cost, London: New Policy Institute.

Macklin, J. and Rudd, K. 2008, '\$4 Billion to help close the gap for indigenous Australians', media release, 30 November 2008.

Mission Australia 2009, An Icon for Exit: The Mission Australia Centre 20052008.

National Youth Commission 2008, Inquiry into Youth Homelessness.

Newman, L., Biedrzycki, K., Patterson, J. and Baum, F. 2007, A Rapid Appraisal Case Study of South Australia's Social Inclusion Initiative, a report prepared for the Social Exclusion Knowledge Network of the Commission on Social Determinants of Health (established by the World Health Organisation).

New South Wales Auditor General 2011, 'Two Ways Together: NSW Aboriginal Affairs Plan', Performance Audit.

New South Wales Ombudsman 2011, Addressing Aboriginal disadvantage: the need to do things differently, a Special Report to Parliament under s 31 of the Ombudsman Act 1974.

Ozdowski, S. 2001, 'The Human Rights of Mentally Ill People: the HREOC Inquiry and After', Mental Health, Criminal Justice and Corrections Conference, Marrickville, 19 October 2001.

Pinkney, S. and Ewing, S. 2006, Costs and Pathways of Homelessness: Developing Policy Relevant Economic Analyses for the Australian Homelessness Service System. 